\title{
Anemia in Acute Coronary Syndrome: An Overview
}

\author{
Chhabi Satpathy $^{1}$ Nirmal Kumar Mohanty ${ }^{1}$ \\ ${ }^{1}$ Dept. of Cardiology, SCB Medical College \& Hospital, Cuttack, \\ Odisha, India \\ Ind J Car Dis Wom 2021;6:194-198.
}

\begin{abstract}
Address for correspondence Dr. Nirmal Kumar Mohanty, MD DM (Cardiology), Associate Professor, Dept. of Cardiology, SCB Medical College \& Hospital, Cuttack - 753007, Odisha, India

(e-mail: diptinirmal.pattnaik@gmail.com).
\end{abstract}

\begin{abstract}
Anemia is very common in patients with cardiovascular diseases. It has been shown that anemia is an independent risk factor for cardiovascular events in general population and in patients of heart failure and acute coronary syndrome (ACS). Various randomized trials have shown prevalence of anemia to be 10 to $43 \%$ in patients with ACS. The cardiac remodeling in ACS patients results in left ventricular dilation, which further increases myocardial wall stress. In the presence of anemia, this exacerbates ischemia and enhances myocardial necrosis and fibrosis and ultimately the prognosis. At present, modality of treatment of anemia in ACS patients is less established except blood transfusion. Anemia at admission may have both short- and long-term worse

Keywords

- Acute Coronary Syndrome

- anemia

- blood transfusion prognosis. Restrictive strategy of blood transfusion, as shown by REALITY trial, may have at least short-term beneficial effect. Due attention should also be given to hospital-acquired anemia (HAA) and anemia developing later, that is, after discharge from hospital. Intravenous iron therapy may be the future therapeutic option, as evidenced by its beneficial effect in treatment of heart failure with anemia.
\end{abstract}

\section{Introduction}

Anemia is very much prevalent in general population and also in patients with cardiovascular diseases. It is associated with both short- and long-term worse prognosis in patients of acute coronary syndrome (ACS). Anemia is also associated with increased prevalence of other comorbidities in patients of ACS at index hospitalization. ${ }^{1-5}$ Therefore, it is thought to be a marker of the disease severity rather than the cause of severity of illness. In patients of ACS, anemia may be present at the time of presentation or may develop during hospitalization or after discharge from hospital. The causes of anemia are many, like inadequate erythropoietin due to primary bone marrow malfunction, renal failure causing reduced synthesis of erythropoietin, or due to hemodilution in the setting of heart failure in ACS. ${ }^{6}$ Gastrointestinal bleeding due to use of antiplatelet drugs like aspirin and clopidogrel may be an important cause of anemia in ACS.

Nutritional deficiency like iron, vitamin $B_{12}$, and folic acid are important causes of anemia in patients of ACS, mostly in the elderly population.

Anemia should be corrected to provide adequate $\mathrm{O}_{2}$ supply to the jeopardized myocardium at the earliest. This restores myocardial viability along with the guidelinedirected medical treatment. Complications like bleeding following treatment with antiplatelets, anticoagulants, and thrombolytic agents may complicate the situation, more so in presence of anemia. The aim and objective of this article is to discuss about the epidemiology, pathophysiology, prognosis, and management strategy in patients with ACS.
DOI https://doi.org/ 10.1055/s-0041-1736255. ISSN 2455-7854. (c) 2021. Women in Cardiology and Related Sciences. All rights reserved.

This is an open access article published by Thieme under the terms of the Creative Commons Attribution-NonDerivative-NonCommercial-License, permitting copying and reproduction so long as the original work is given appropriate credit. Contents may not be used for commercial purposes, or adapted, remixed, transformed or built upon. (https://creativecommons.org/ licenses/by-nc-nd/4.0/)

Thieme Medical and Scientific Publishers Pvt. Ltd., A-12, 2nd Floor, Sector 2, Noida-201301 UP, India 


\section{Definition of Anemia}

Accurate definition of anemia involves absolute decrease of red blood cell (RBC) mass determined by radiolabeled blood volume analysis. ${ }^{7}$ But in clinical practice, parameters like $\mathrm{Hb}$ $\%$ and hematocrit (Hct) are used to diagnose anemia. As per the 1968 WHO group report, anemia is diagnosed with $\mathrm{Hb}$ $\%<13 \mathrm{~g} / \mathrm{dl}$ in adult men and $<12 \mathrm{~g} / \mathrm{dl}$ in adult nonpregnant women. ${ }^{8}$

\section{Clinical Determinants of Hb Levels}

Various workers have worked on normal Hb\% level in their study population. Normal Hb\% level may vary according to age, sex, and race. People of African ancestry have at least $0.5 \mathrm{~g} / \mathrm{dl}$ lower $\mathrm{Hb} \%$ compared to Caucasians. Elderly people ( $>60$ years) have lower $\mathrm{Hb} \%$ compared to younger adults. ${ }^{9}$ In one study, anemia was present in $43 \%$ of elderly patients admitted for acute heart failure. ${ }^{10}$ So, anemia may be a marker and not a cause of an underlying disease state in elderly population. Anemia in elderly patients should be evaluated properly and corrected whenever possible. ${ }^{11} \mathrm{He}-$ modilution may be the cause of anemia in patients of ACS with heart failure. This may be found in as high as $40 \%$ to $46 \%$ of patients when determined accurately by measurement of RBC mass relative to plasma volume using 131 tagged albumin. $^{7,12}$

\section{Epidemiology of Anemia in ACS}

Anemia in ACS may be multifactorial. It may be existing prior to hospitalization for ACS. Anemia may develop during hospitalization, that is, HAA or may appear after discharge, mostly due to adverse effect of drugs, that is, antiplatelets or anticoagulants.

\section{On- Admission Anemia:-}

Anemia on admission is found to be associated with adverse outcome on long-term follow up. The prevalence of anemia was clinically significant in the ACS patients of MINAP registry in the UK. Anemic patients were older, had multiple comorbidities, and were less likely to receive guidelinedirected medical treatment. Anemia was also independently associated with mortality.

\section{Hospital Acquired Anemia (HAA)}

In the study of Salisbury et $\mathrm{al}^{13}$ the prevalence of HAA was $57 \%$. Mild anemia $(\mathrm{Hb}>11 \mathrm{~g} / \mathrm{dl})$ was present in $37 \%$ of patients. Moderate HAA ( $\mathrm{Hb} 9-11 \mathrm{~g} / \mathrm{dl}$ ) and severe HAA $(\mathrm{Hb}<9 \mathrm{~g} / \mathrm{dl})$ were present in $15 \%$ and $5 \%$ patients, respectively. In-hospital determinants of HAA were almost same as those present on admission like age, female sex, cardiogenic shock, acute renal failure, chronic kidney disease (CKD), and extensive use of antiplatelets and anticoagulants.

In-hospital mortality due to HAA was according to its severity. It was with odds ratio (OR) of 1.38 (95\% confidence interval [CI]: 1.10-1.73) in mild-to-moderate HAA and OR of 3.39 (95\% CI 2.59-4.44) in severe HAA. ${ }^{13}$ One-year mortality and cardiovascular morbidity were also higher in one study. $^{14}$

\section{New Onset Anemia Postdischarge}

New onset anemia is defined as decrease of $\mathrm{Hb}$ at least $0.5 \mathrm{~g} / \mathrm{dl}$ compared to hospital discharge value ${ }^{15}$ In patient of ACS, whose HAA improved overtime had similar long-term outcome, that is, all-cause mortality and rehospitalization in acute heart failure as compared to those having no anemia at admission (hazard ration [HR] 0.8, 95\% CI: 0.5-1.3). Conversely, there was increased trend in patient with persistent (HR 1.8, 95\% CI: 1.2-2.5) or new onset (HR 1.9, 95\% CI: 1.13.3) anemia. $^{15}$

\section{Pathophysiology of Anemia in ACS}

The concept, "anemia of inflammation" may be the appropriate term in patients of ACS. It is reflection of the systemic inflammatory response syndrome (SIRS). Cytokines like interleukin (IL)-1, IL-6, tumor necrosis factor (TNF) $\alpha$, interferon (IFN) $\Upsilon$ and transforming growth factor (TGF) $\beta$ play major roles in pathogenesis of anemia in ACS (-Table 1). Mild anemia in ACS may be due to chronic inflammation, that is, anemia of chronic disease (ACD). ${ }^{16}$

The study by Mamas et al $^{17}$ showed anemia to be associated with several other preexisting risk factors in patients with ACS, that is, smoking, hyperlipidemia, previous myocardial infarction, previous heart failure, previous stroke, previous vascular disease, diabetes mellitus, renal disease, and chronic obstructive pulmonary disease.

Moderate anemia is associated with severe RBC dysfunction and reduced nitric oxide (NO) in blood. Vascular and cardiac nitric oxide synthase (eNOS) are also essential for the cardiocirculatory adaptation to anemia. So vascular and cardiac eNOS should be upregulated to compensate for reduced circulating NO in anemia. RBC dysfunction with eNos dysfunction may adversely affect the outcome in ACS. But endothelial dysfunction, which is associated with various comorbidities along with anemia, might contribute to left ventricular (LV) dysfunction in ACS. Patients with ACS along with diabetes and CKD (III-V) have the worst prognosis when anemia is coexisting. It doubles the 10 -year mortality in these patients. ${ }^{18}$

Table 1 Cytokine-mediated inflammatory response in ACS (IL-1, IL-6, TNF $\alpha$, IFN $\Upsilon$, TGF $\beta$ )

\begin{tabular}{|l|}
\hline a. Reduced half-life of RBC \\
\hline $\begin{array}{l}\text { b. Bioavailability of iron is reduced, so hemopoiesis is } \\
\text { reduced }\end{array}$ \\
\hline c. Reduced erythropoietin production \\
\hline
\end{tabular}

Abbreviations: ACS, acute coronary syndrome; RBC, red blood cell. 


\section{Iron Deficiency Anemia in ACS}

The clinical significance of iron deficiency anemia in ACS patients is unclear. There is definite link between hypoxia, myocardial ischemia, and iron metabolism. Iron has protective immunomodulatory effect on macrophages, helps in healing of infarct myocardium, and improves global LV remodeling in cases of ACS. ${ }^{19}$

\section{Treatment of Anemia in ACS}

The treatment options for anemia in ACS are limited. The CONCORDANCE database of Australian ACS population shows anaemic patients with ACS are less likely to undergo invasive and thrombolytic therapy in view of anticipation of bleeding complications.

The preventive strategy to avoid bleeding compromises the guideline-directed medical treatment. These patients are less likely to receive dual antiplatelet therapy and anticoagulation. STEMI (ST-segment elevation myocardial infarction) patients are less likely to get thrombolysis or primary percutaneous intervention (PPCI). In-hospital complication of reinfarction, heart failure, and renal failure are common in anemic patients. ${ }^{20}$

\section{Role of PRBC in Anemia of ACS}

Theoretically, RBC transfusion looks promising by increasing O2 delivery to vulnerable myocardium, thereby reducing ischaemic symptoms. The beneficial effect of packed RBC (PRBC) transfusion may be counterbalanced by reduced $\mathrm{O}_{2}$ delivery, due to rapid depletion of red cell NO content during storage. The increase in Hct also increases blood viscosity, which causes slugging of capillaries and reduces delivery of $\mathrm{O}_{2}$ to myocardium. ${ }^{21}$ Other complications related to PRBC transfusion are circulatory overload, immune-mediated transfusion reaction, and transfusion-related acute lung injury. ${ }^{22}$

There are two strategies of PRBC transfusion in patients of ACS: restrictive and liberal transfusion ( - Table 2 ).

There are limited number of studies focusing on benefits of PRBC transfusion in ACS patients.

The TRICC trial by Hobert et al showed higher mortality among patients with restrictive transfusion than liberal one (26\% vs. $21 \%$; $p$-value 0.03 ). ${ }^{23}$

The CRUSADE registry by Alexander et al involving 44,242 non-ST-segment elevation (NSTE) ACS patients showed RBC transfusion had favorable outcome in patients with hematocrit of $<24 \%$ but higher mortality in patients with Hct $>30 \%{ }^{24}$

Table 2 Restrictive versus liberal transfusion

\begin{tabular}{|l|l|l|}
\hline $\begin{array}{l}\text { Type of transfusion } \\
\text { threshold }\end{array}$ & Restrictive & Liberal \\
\hline & $\begin{array}{l}\text { Transfusion is } \\
\text { not indicated } \\
\text { until Hb level } \\
\text { is }<7 \text { to } 8 \mathrm{~g} / \mathrm{dl} .\end{array}$ & $\begin{array}{l}\text { Transfusion is } \\
\text { not indicated } \\
\text { until Hb level } \\
\text { is }<9 \text { to } 10 \mathrm{~g} / \mathrm{dl} .\end{array}$ \\
\hline
\end{tabular}

The pilot trial, that is, CRIT by Cooper et al categorized patients of ACS to conservative group with $\mathrm{Hct}<24 \%$ with a target Hct 24 to $27 \%$ and liberal group with $\mathrm{Hct}<30 \%$ with a target Hct of 30 to $33 \%$. A higher rate of primary endpoint, that is, composite of in-hospital death, recurrent AMI, or new-onset or worsening heart failure in liberally transfused group was found compared to conservative group (38\% vs. $13 \% ; p=0.046) .{ }^{25}$ The difference was mainly due to higher incidence of new or worsening heart failure. NICE guidelines stated that the optimal transfusion threshold for patients with ongoing ACS should be 8 to $10 \mathrm{~g} / \mathrm{dl}^{26}$

American Association of Blood Bank guidelines states that restrictive $\mathrm{RBC}$ transfusion threshold cannot be applied to ACS patients who are not hemodynamically stable. ${ }^{27}$

REALITY trial was the randomized trial of transfusion and strategies in patients with MI and anemia. It showed that a restrictive PRBC transfusion strategy (transfusion for $\mathrm{Hb}<8$ $\mathrm{g} / \mathrm{dl}$, goal $\mathrm{Hb} 8-10 \mathrm{~g} / \mathrm{dl}$ ) is noninferior to a more liberal strategy (transfusion for $\mathrm{Hb}<10 \mathrm{~g} / \mathrm{dl}$, goal $\mathrm{Hb}>11 \mathrm{~g} / \mathrm{dl}$ ). ${ }^{28}$ Total cost toward PRBC transfusion was also less in view of limited availability in presence of increased demand in clinical practice. Incidence of infection $(0 \% \mathrm{vs.} 1.5 \% p=0.03)$ and acute lung injury ( $0.3 \%$ vs. $2.2 \% ; p=0.03$ ) were less in restrictive strategy group.

Very often, anemia in ACS is associated with other comorbidities like heart failure and chronic renal failure. Intravenous iron therapy may be the option to treat these patients. Iron therapy may improve exercise tolerance (6-minute walk time) and symptomatic New York Heart Association (NYHA) class. ${ }^{29,30}$ It may have immunomodulatory activity and may increase the risk of infection. ${ }^{31}$

In view of paucity of evidence based on randomized controlled trials, RBC transfusion should be restricted to patients with $\mathrm{Hb}$ level $<8.0 \mathrm{~g} / \mathrm{dl}$ and better avoided when $\mathrm{Hb}$ level is $>10 \mathrm{~g} / \mathrm{dl}$. In patients with $\mathrm{Hb}$ level between 8 to $10 \mathrm{~g} / \mathrm{dl}, \mathrm{RBC}$ transfusion should be prioritized to individual patients, as the clinical situation demands.

\section{Role of Erythropoietin in Anemia of ACS}

Various experimental models have shown that the hematopoietic hormone erythropoietin (Epo) produced by kidney in response of hypoxia has cardioprotective action. ${ }^{32}$ It stimulates hematopoiesis and promotes neovascularization and angiogenesis by mobilization of endothelial progenitor cells. $^{33,34}$ It also has anti-inflammatory, antioxidative, and antiapoptotic activities. ${ }^{35,36}$

However, the Regeneration of Vital myocardium in STSegment Elevation Myocardial infarction by Erythropoietin (REVIVAL)-3 trial showed short-term use of intravenous erythropoietin (Epoetin beta) in PCI-treated STEMI patients did not improve clinical long-term prognosis. Rather the Reduction of infarct Expansion and Ventricular remodeling with Erythropoietin After Large myocardial infarction (REVEAL) study showed that there was an increasing trend for risk of death, MI, and stroke associated with Epo therapy. ${ }^{37,38}$

Reduction of Events with Darbepoetin alfa in Heart Failure (RED-HF) trial. Treatment with darbepoetin alfa did not improve clinical outcome in symptomatic heart failure 
patients with anemia as compared to placebo. Rather, thrombotic complications including stroke were higher in the darbepoetin alfa group.

The real-world scenario from CONCORDANCE registry of Australia: The ACS patients having anemia were thrombolysed less frequently than nonanemic patients (22\% vs. $33 \%$; $p<0001$ ) and primary PCI was less common (45\% vs. $51 \%$, $p=0.033$ ). In subgroup of ACS patients, that is, STEMI, NONSTEMI, and unstable angina, anemic patients had less coronary angiography (63\% vs. $86 \% ; p<0.0001$ ), and PCI (30\% vs. $52 \% ; p<0.0001)$ was less in anemic patients. Use of antiplatelet agents, more so the potent ones like prasugrel (2\% vs. $5 \% ; p<0.0001$ ) and ticagrelor ( $11 \%$ vs. $20 \% ; p<0.0001$ ), was less in anemic patients. Anticoagulation with heparin, either unfractionated or low-molecular weight ones, was less commonly used in anemic patients ( $82 \%$ vs. $88 \% ; p<0.0001$ ).

Anemia was associated with increased incidence of cardiogenic shock ( $5 \%$ vs. $2 \% ; p<0.0001$ ), recurrent ischemia (13\% vs. $8 \%$ ), reinfarction ( $4 \%$ vs. $2 \% ; p<0.0001$ ), and death from all causes ( $7 \%$ vs. $3 \% ; p<0.0001$ ). So, anemia per se and in collaboration with other risk factors like diabetes mellitus (DM) and CKD play an important role in management of ACS. The bleeding complications following therapy with antiplatelets, anticoagulants, and thrombolytic agents complicates the overall outcome in patients of ACS having anemia. ACS patients having anemia on admission or developing it during hospitalization may not be given antiplatelets and anticoagulants. The patients undergoing PCI having bleeding subsequently are very much at risk of stent thrombosis, due to withdrawal of antiplatelets and may have fatal outcome.

\section{Prognosis of Anemia in ACS}

Moderate-to-severe anemia may have short- and long-term worse prognosis in patients of ACS. These patients may not receive guideline-directed medical treatment. But judicious use of drugs and proper selection of patients for interventional procedures may avert the bleeding complications and the ultimate prognosis. In the UK MINAP registry comprising a cohort of 422,855 patients with ACS, angiography conducted with anaemic and nonanemic group was similar. The impact of anemia on mortality was independent and almost comparable across the ACS spectrum. ${ }^{17}$ The data from Biennial Israeli ACS registry (ACSIS) has shown that universal approach by radial PCI has reduced the in-hospital bleeding complications. ${ }^{39}$ More selective use of heparin and glycoprotein (GP IIb/IIIa) receptor blockers have contributed to this also.

\section{Conclusion}

Anemia is very much prevalent in significant number of ACS patients and is associated with both short- and long-term prognosis including mortality. However, there is still uncertainty, as to whether anemia is a marker of underlying severity of disease or has a direct effect on prognosis in ACS. Till now, only PRBC transfusion is the treatment of choice for anemia with $\mathrm{Hb}<8 \mathrm{~g} / \mathrm{dl}$, except for hemodynami- cally unstable ACS patients, who could benefit from Hb level between 8 and $10 \mathrm{~g} / \mathrm{dl}$. But it is not free from complications.

In ACS patients, assessment of severity of anemia and its management should be done with judicious use of drugs, which may likely cause bleeding and further worsen the clinical condition. PCI, preferably by radial access, may lessen further deterioration of anemia due to bleeding. Intravenous iron may be the new therapeutic option for management of anemia in patients of ACS.

Conflict of Interest

None declared.

\section{References}

1 Riley RF, Newby LK, Don CW, et al. Guidelines-based treatment of anaemic STEMI patients: practice patterns and effects on inhospital mortality: a retrospective analysis from the NCDR. Eur Heart J Acute Cardiovasc Care 2013;2(01):35-43https://doi.org/ 10.1177/ 2048872612471216 PMID: 24062932

2 Paul B, Wilfred NC, Woodman R, Depasquale C. Prevalence and correlates of anaemia in essential hypertension. Clin Exp Pharmacol Physiol 2008;35(12):1461-1464

3 Shu DH, Ransom TP, O'Connell CM, et al. Anemia is an independent risk for mortality after acute myocardial infarction in patients with and without diabetes. Cardiovasc Diabetol 2006;5:8

4 Babitt JL, Lin HY. Mechanisms of anemia in CKD. J Am Soc Nephrol 2012;23(10):1631-1634

5 Young JB, Abraham WT, Albert NM, et al; OPTIMIZE-HF Investigators and Coordinators. Relation of low hemoglobin and anemia to morbidity and mortality in patients hospitalized with heart failure (insight from the OPTIMIZE-HF registry). Am J Cardiol 2008;101(02):223-230

6 Meneveau N, Schiele F, Seronde MF, et al; Reseau de Cardiologie de Franche Comte. Anemia for risk assessment of patients with acute coronary syndromes. Am J Cardiol 2009;103(04):442-447

7 Androne AS, Katz SD, Lund L, et al. Hemodilution is common in patients with advanced heart failure. Circulation 2003;107(02): 226-229

8 Blanc B, Finch CA, Hallberg L, et al. Nutritional Anemias. Report of a WHO Scientific Group. WHO Tech Rep Ser. 1968;405:1-40

9 Beutler E, Waalen J. The definition of anemia: what is the lower limit of normal of the blood hemoglobin concentration? Blood 2006;107(05):1747-1750

10 Wu WC, Rathore SS, Wang Y, Radford MJ, Krumholz HM. Blood transfusion in elderly patients with acute myocardial infarction. $\mathrm{N}$ Engl J Med 2001;345(17):1230-1236

11 Morici N, Cantoni S, Antonicelli R, et al. Anemia in octogenarians with non-ST elevation acute coronary syndrome: aging or disease? Int J Cardiol 2014;176(03):1147-1149

12 Mancini DM, Katz SD, Lang CC, LaManca J, Hudaihed A, Androne AS. Effect of erythropoietin on exercise capacity in patients with moderate to severe chronic heart failure. Circulation 2003;107 (02):294-299

13 Salisbury AC, Amin AP, Reid KJ, et al. Hospital-acquired anemia and in-hospital mortality in patients with acute myocardial infarction. Am Heart J 2011;162:300-309

14 Meron O, Cladellas M, Recasens L, et al. [In-hospital acquired anemia in acute coronary syndrome. Predictors, in-hospital prognosis and one- year mortality.]. Rev Esp Cardiol 2012;65(08): 742-748Spanish

15 Hasin T, Sorkin A, Markiewicz W, Hammerman H, Aronson D. Prevalence and prognostic significance of transient, persistent, and new-onset anemia after acute myocardial infarction. Am J Cardiol 2009;104(04):486-491 
16 Weiss G, Goodnough LT. Anemia of chronic disease. N Engl J Med 2005;352(10):1011-1023

17 Mamas MA, Kwok CS, Kontopantelis E, et al. Relationship between anemia and mortality outcomes in a national ACS cohort: insights from the UK MINAP registry. J Am Heart Assoc 2016;5:e003348

18 Vlagopoulos PT, Tighiouart H, Weiner DE, et al. Anemia as a risk factor for cardiovascular disease and all-cause mortality in diabetes: the impact of chronic kidney disease. J Am Soc Nephrol 2005;16(11):3403-3410

19 Siglienti I, Bendszus M, Kleinschnitz C, Stoll G. Cytokine profile of iron-laden macrophages: implications for cellular magnetic resonance imaging. J Neuroimmunol 2006;173(1-2):166-173

20 Huynh R, Hyun K, D'Souza M, et al. Outcomes of anemic patients presenting with acute coronary syndrome: an analysis of the Cooperative National Registry of Acute Coronary Care, Guideline Adherence and Clinical Events. Clin Cardiol 2019; 42:791-796

21 Tsai AG, Cabrales P, Intaglietta M. Microvascular perfusion upon exchange transfusion with stored red blood cells in normovolemic anemic conditions. Transfusion 2004;44(11):1626-1634

22 Hendrickson JE, Hillyer CD. Noninfectious serious hazards of transfusion. Anesth Analg 2009;108(03):759-769

23 Hebert PC, Wells G, Blajchman MA, et al. A multicentre, randomized, controlled clinical trial of transfusion requirements in critical care. N Engl J Med 1999;340:409-417

24 Alexander KP, Chen AY, Wang TY, et al; CRUSADE Investigators. Transfusion practice and outcomes in non-ST-segment elevation acute coronary syndromes. Am Heart J 2008;155(06):1047-1053

25 Kansagara D, Dyer E, Englander H, Fu R, Freeman M, Kagen D. Treatment of anemia in patients with heart disease: a systematic review. Ann Intern Med 2013;159(11):746-757

26 National Institute for Health and Clinical Excellence. Transfusion: NICE guideline NG24. Accessed August 11, 2021 at: http://www. nice.org.uk/guidance/ng24/evidence/full-guidance-2177160733

27 Carson JL, Guyatt G, Heddle NM, et al. Clinical practice guidelines from the AABB red blood cell transfusion thresholds and storage. JAMA 2016;316(19):2025-2035

28 Dharam J Kumbhani et al. Randomized trial of Transfusion strategies in patients with Myocardial infarction and Anemia REALITY. 2021:1-4

29 Anker SD, Comin Colet J, Filippatos G, et al;FAIR-HF Trial Investigators. Ferric carboxymaltose in patients with heart failure and iron deficiency. N Engl J Med 2009;361(25):2436-2448. doi: https://doi.org/10.1055/s-0041-1376255

30 Comin-Colet J, Lainscak M, Dickstein K, et al. The effect of intravenous ferric carboxymaltose on health-related quality of life in patients with chronic heart failure and iron deficiency: a subanalysis of the FAIR-HF study. Eur Heart J 2013;34(01): 30-38

31 Litton E, Xiao J, Ho KM. Safety and efficacy of intravenous iron therapy in reducing requirement for allogeneic blood transfusion: systematic review and meta-analysis of randomised clinical trials. BMJ 2013;347:f4822

32 Sanchis-Gomar F, Garcia-Gimenez JL, Pareja-Galeano H, Romagnoli M, Perez-Quilis C, Lippi G. Erythropoietin and the heart: physiological effects and the therapeutic perspective. Int J Cardiol 2014;171(02):116-125

33 Heeschen C, Aicher A, Lehmann R, et al. Erythropoietin is a potent physiologic stimulus for endothelial progenitor cell mobilization. Blood 2003;102(04):1340-1346

34 van der Meer P, Lipsic E, Henning RH, et al. Erythropoietin induces neovascularization and improves cardiac function in rats with heart failure after myocardial infarction. J Am Coll Cardiol 2005; 46(01):125-133

35 Anagnostou A, Liu Z, Steiner M, et al. Erythropoietin receptor mRNA expression in human endothelial cells. Proc Natl Acad Sci U S A 1994;91(09):3974-3978

36 Wright GL, Hanlon P, Amin K, Steenbergen C, Murphy E, Arcasoy MO. Erythropoietin receptor expression in adult rat cardiomyocytes is associated with an acute cardioprotective effect for recombinant erythropoietin during ischemia-reperfusion injury. FASEB J 2004;18(09):1031-1033

37 Ott I, Schulz S, Mehilli J, et al; REVIVAL-3 Study Investigators. Erythropoietin in patients with acute ST-segment elevation myocardial infarction undergoing primary percutaneous coronary intervention: a randomized, double-blind trial. Circ Cardiovasc Interv 2010;3(05):408-413

38 Fokkema ML, Kleijn L, van der Meer P, et al. Long term effects of epoetin alfa in patients with ST- elevation myocardial infarction. Cardiovasc Drugs Ther 2013;27(05):433-439

39 Najjar SS, Rao SV, Melloni C, et al; REVEAL Investigators. Intravenous erythropoietin in patients with ST-segment elevation myocardial infarction: REVEAL: a randomized controlled trial. JAMA 2011;305(18):1863-1872 